\title{
Reacomodos de población en Tzintzuntzan durante el siglo XVI
}

\author{
Population Readjustments in \\ Tzintzuntzan in the 16th Century
}

\author{
José Manuel Martínez Aguilar \\ Universidad Michoacana de San Nicolás de Hidalgo, México \\ majmanuel999@hotmail.com
}

Resumen: Las congregaciones o reducciones de pueblos de indios se tienen bien documentados para numerosos pueblos de Nueva España. En el caso específico de Tzintzuntzan se ha dudado si en realidad este proceso se llevó a cabo, pues no se ha encontrado el acta de su congregación. Después de analizar distintos manuscritos coloniales, crónicas, estudios previos, tradición oral, así como la traza urbana de la ciudad, se deduce que Tzintzuntzan tuvo al menos dos momentos de reorganización urbano-social. El primero que se llevó a cabo en la década de 1530 con la reubicación del convento y una parte de la población que estaba asentada en las laderas del cerro Tariácuri. El segundo debió llevarse a cabo a finales del siglo XVI o principios del xviI, con el traslado de varios de sus barrios sujetos hacia la cabecera.

Palabras clave: congregaciones; fundaciones; Tzintzuntzan; Michoacán; Nueva España.

Abstract: The congregations or reductions of Indian peoples have been widely documented for many peoples of New Spain. In the specific case of Tzintzuntzan, there was some doubt as to whether this process actually took place, since no records had been found. An analysis of various colonial manuscripts, chronicles, previous studies, the oral tradition and the urban 
layout of the city shows that Tzintzuntzan had undergone at least two moments of urban social reorganization. The first took place in the 1530s with the relocation of the convent and part of the population that lived on the slopes of Tariacuri Hill. The second must have been carried out in the late 16 th or early 17 th centuries, with the transfer of several of its neighborhoods to the head town.

Key words: congregations; foundations; Tzintzuntzan; Michoacan; New Spain.

Fecha de recepción: 7 de mayo de 2015 Fecha de aceptación: 3 de agosto de 2015

\title{
INTRODUCCIÓN
}

\begin{abstract}
A l arribar los primeros españoles a Michoacán, los asentamientos humanos tenían un patrón disperso, generalmente dispuestos sobre las laderas de los cerros. Por su importancia y número de habitantes, únicamente Tzintzuntzan podía ser considerada como "ciudad" -aunque no en la concepción europea de lo que debía ser una ciudad ordenada-, el resto de las poblaciones eran de menor jerarquía y estaban compuestas de caseríos intercalados con parcelas de labranza (Castro, 2004, p. 75).

En el caso particular de Tzintzuntzan, se cree que la población que habitaba las laderas de los cerros Yahuarán o Yahuarato y Tariácuri al contacto con los españoles (Pollard, 1977) en algún momento fue reacomodada a poca distancia en el valle (Warren, 1977, p. 116). Aunque no se ha localizado el acta de congregación, se tienen elementos para creer que los pueblos sujetos a Tzintzuntzan también fueron trasladados a la cabecera en las postrimerías del siglo XVI o los primeros años del siguiente siglo.

Para encontrar pistas de estos reacomodos de población, si es que los hubo, se revisaron distintos manuscritos de archivo, crónicas coloniales, estudios previos y tradición oral, además de observar la traza urbana de la ciudad y hacer una exploración superficial de campo.
\end{abstract}

\section{()(1) $(3$}




\section{LAS CONGREGACIONES O REDUCCIONES}

Desde los primeros años después de la conquista de Tenochtitlan, las autoridades españolas advirtieron la dificultad del control político, del aprovechamiento de la mano de obra de la población, la recaudación de tributos, el control de los territorios, el aprovechamiento de los recursos naturales y el adoctrinamiento, al tener una población dispersa y "desordenada", según su concepción de orden (Pérez, 2009, p. 20). Fue por ello que la política congregacional -también llamada concentración o reducción- de los pueblos de indios encontró el apoyo, no sólo de la corona, sino de los misioneros, los obispos y las autoridades civiles. Las congregaciones se daban básicamente de tres maneras: trasladando grupos de población para formar un nuevo pueblo -fundación-, reacomodando el patrón de los asentamientos existentes de dispersos a concentrados y trasladando grupos de población a un asentamiento de mayor jerarquía, que regularmente había fungido como cabecera política y/o parroquial.

Las congregaciones que se impulsaron en las primeras décadas del siglo XVi eran voluntarias, mientras que las de finales del mismo siglo eran de carácter obligatorio. En la legislación se estipulaba que los sitios en que se llevaran a cabo debían gozar de agua, tierras, montes y caminos accesibles, sin que se mezclaran con los de los españoles. Por desgracia, muchos de los traslados fueron perjudiciales para los indios, porque eran congregados con grupos étnicos distintos o en lugares de climas a los que no estaban habituados, entre otros inconvenientes (Torre, 1995, pp. 9-10).

Los franciscanos fueron de los primeros en atender el enorme problema que representaba la extensión territorial y dispersión demográfica, que dificultaban su labor de evangelización, entendiendo que evangelizar significaba no solamente cristianizar, sino también transformar a los indios en hombres occidentales (Rubial, 1990, p. 144).

Los dirigentes españoles estaban convencidos de las ventajas de la vida urbana, donde se podía vivir en policía, es decir, dentro de un orden civil sujeto a leyes, instituciones, costumbres y religión católica en los territorios que iban conquistando, por lo que desde la segunda década del siglo XVI se fundó gran cantidad de ciudades, villas y pueblos por todo el virreinato de Nueva España, originalmente concebidos de manera separada los asentamientos de españoles y de indios. Sobre todo en la última década del

\section{()(1) $\$$}


siglo XVI y principios del XVII se congregaron no pocos pueblos de indios (Torre, 1995).

En Michoacán, la concentración de poblaciones nativas en pueblos trazados de nuevo o reorganizados inició en 1533 por parte de los franciscanos, incluso antes de las disposiciones oficiales (Salazar, 2008, p. 169), siendo prototipo para los pueblos planeados en el futuro (Gerhard, 1986). El proceso fundacional de los nuevos territorios contempló además la reorganización política y económica de los pueblos de indios, la construcción de templos, conventos, hospitales, acueductos y otras obras necesarias para el funcionamiento de los mismos.

En su primera visita a Nueva España, el licenciado Vasco de Quiroga también advirtió los inconvenientes de la dispersión de la población, por lo que envió su famosa "Carta al Consejo" donde recomendaba al Consejo de Indias que se concentrara a los naturales en pueblos donde pudieran sobrevivir económicamente y gobernarse por sí mismos, contando con la predicación y la educación de los frailes, de manera que se apartaran de sus vicios y malas conductas y se favorecieran sus buenas costumbres. Consideraba que con la congregación se resolverían los atropellos contra ellos, que eran "inocentes, humildes y obedientes", pero como tenían abundancia de tierra "les nace tanta ociosidad, flojedad y descuido, lo cual conviene que se le quite con alguna buena orden de república y policía” (Warren, 1997, p. 38).

En relación con la manera en como los franciscanos realizaban las fundaciones, Espinosa señala el siguiente procedimiento: "luego que los tenía congregados, se iniciaba el trazo de calles, plazas y edificios administrativos y la repartición de los lotes; dejando el convento como punto de partida hacia los cuatro puntos cardinales". Después "los instruían en el modo que habían de observar en su gobierno, componiendo sus repúblicas y trayendo maestros de todos los oficios para que los aprendiesen y así salieron los tarascos tan grandes oficiales" (Espinosa, 2003, p. 125).

Con base en una descripción de la congregación -fundación- de Acámbaro en 1535 , se puede entender con mayor claridad cómo era este procedimiento en otros casos. Primero se erigía

...una gran cruz de madera en el lugar elegido para la congregación, cumpliendo con las solemnidades correspondientes, esparciendo un puñado de

\section{()(1) $(3$}


tierra por el lugar, en señal de posesión. Posteriormente se desmontaba el sitio y se trazaban las calles y plazas del pueblo. Junto a la cruz cercana a la capilla de visita se colgaban una o dos campanas, y se repicaban para congregar a la población y celebrar de manera solemne una misa. Enseguida se iniciaba el proceso de reparto de terrenos para la construcción de casas, destinándose también ciertos espacios para la plantación de jardines y huertas, que servían posteriormente para el sostenimiento del convento. Después se efectuaba una especie de desfile con los indios congregados y se procedía a nombrar a las autoridades del pueblo: gobernador, alcaldes y regidores (Beaumont, 1985, t. II, p. 250).

Cuando los pueblos ya estaban trazados, los nuevos pobladores trasladados eran acomodados juntos en una de las orillas del pueblo y se les permitía tener su propia capilla, aunque fuera modesta. Para evitar que estos regresaran a sus lugares de origen, las iglesias, ermitas y conventos de los pueblos abandonados eran demolidos y sus casas quemadas (Castro, 2004, p. 86).

Sobre el caso de Cocupao, se sabe que el pueblo fue congregado en 1534, a poca distancia de su ubicación original. La tarea estuvo a cargo del regidor de Tzintzuntzan don Antonio Huitziméngari, el gobernador don Diego Zirauata y, aunque no lo menciona, probablemente el guardián del convento franciscano de Tzintzuntzan fray Jerónimo de Alcalá, quienes fijaron los límites del nuevo pueblo, poniendo mojoneras y sembrando nopales en toda la periferia; después de haber hecho el trazo se repartieron los solares. ${ }^{1}$

Según Arvizu la traza urbana variaba de un pueblo a otro. Esta podía ser regular: definida por calles ortogonales que formaban manzanas cuadradas o rectangulares, donde la plaza, el templo o el convento ocupaban la parte central. El trazado semirregular se diferenciaba del regular en que el damero que formaban las calles se adaptaba libremente a la topografía o porque se reutilizaban los caminos prehispánicos no regulares. La traza mixta era la combinación de traza regular y la semirregular. Por

${ }^{1}$ Fondo José Corona Nuñez. Serie escritos. Caja 18, exp. 23, f. 36. Archivo Histórico Documental del Instituto de Investigaciones Históricas-Universidad Michoacana de San Nicolás de Hidalgo (AhDiıн-umsnh), Morelia, México.

\section{(ㅇ)(1) $(3$}


último la traza lineal era característica común a los poblados desarrollados a lo largo de los caminos, generalmente por generación espontánea (Arvizu, 1993, pp. 28-31). En algunos pueblos, como Pátzcuaro y Tzintzuntzan, la traza ortogonal se tuvo que superponer a los caminos prehispánicos, que podrían describirse como irregulares u orgánicos, teniendo como resultado una red mixta.

Si bien se tienen ejemplos sobre los procedimientos que debían adoptarse para la congregación y fundación de pueblos, villas y ciudades, lo cierto es que antes de las Ordenanzas de Felipe II en 1573, estos eran ambiguos e imprecisos, tal como se puede ver en las instrucciones dictadas por el virrey Velasco en 1559, donde mandó que las reducciones se hicieran "en traza cerca de las iglesias y monasterios [...] para que vivan en policía cristiana, sin quitarles sus usos y costumbres los que no son notoriamente injustos y tiranos [...] porque es cierto que, como estaban dispersos por montes, sierras y barrancas, no se podía tener cuenta con el patrimonio de Jesucristo ni con el de vuestra majestad" (Paso y Troncoso, 1939, p. 261).

En respuesta al precepto de Velasco y otros mandamientos emitidos entre 1550 y 1564 en Nueva España (Gerhard, 1986, p. 27), se congregaron numerosos pueblos, pero aun así, a finales del siglo xvi seguían existiendo poblaciones dispersas. En el caso de Michoacán, que había tenido una caída de población en la tercera década del mismo siglo a causa de una epidemia conocida como cocoliztli, el procurador de los indios de Nueva España, Pedro Díaz de Agüero, por mandato de don Luis de Velasco y Castilla, ordenó en 1595 a dirigentes de diferentes pueblos de indios y guardianes de conventos que congregaran algunos de sus barrios sujetos en las partes que les parecieren más conveniente, con la finalidad de que los naturales "vivieran en policía y pudieran ser adoctrinados con más facilidad y utilidad de ellos". No obstante, estas tampoco se llevaron a cabo con la rapidez y efectividad que se esperaba, por lo que tres años después se comisionó a diferentes jueces para que colaboraran en la reducción de un grupo de pueblos que seguían dispersos (Paredes, Cárdenas, Piñón, Pulido, 1994, pp. 500-504). De acuerdo con estas disposiciones los que tenían un número considerable de habitantes, convento, fuentes de agua y otras cualidades, tenían más posibilidades de no ser reubicados, sino que eran candidatos a captar la población de barrios sujetos o de menor jerarquía.

\section{()(1) $\$$}




\section{TZINTZUNTZAN: DEL CERRO TARIÁCURI AL VALLE}

Como es sabido, los primeros franciscanos encabezados por fray Martín de Coruña -o Jesús-, llegaron a la antigua capital tarasca a finales de 1525 . Según Alcalá, lo primero que hizo el fraile fue entrevistarse con el último emperador tarasco Tangaxoan II, quien había adoptado el nombre cristiano de Francisco, para pedirle un lugar en donde edificar una casa y una iglesia, "y con el trabajo de los indios de Tzintzuntzan, construyeron una iglesia de madera y un monasterio de adobe con celdas techadas de paja, acordes con el ideal franciscano de pobreza [...] En esa iglesia fray Martín de Jesús celebró una primera misa con acompañamiento de varios de los instrumentos con los que los indios honraban a sus dioses" (Alcalá, 1980, p. 264). El relato de Beaumont es similar pero agrega que dieron vuelta por todos los barrios para elegir el lugar que les pareciera más propicio (Beaumont, 1985, t. II, p. 250). Escobar, por su lado, señala que durante los siguientes meses después de su llegada fray Martín de Jesús y otros religiosos destruyeron en Tzintzuntzan todos los templos y todos los ídolos, y que "el propio don Francisco, recién bautizado como católico, postró por tierra todos los templos que él había levantado con su mando, y junto a su real palacio levantó templo al señor y queso fuese la patrona la gloriosísima Santa Ana" (Escobar, 2008, p. 292).

Unos años después, los franciscanos trasladaron la iglesia y el convento al valle, a menos de un kilómetro al norte de su ubicación original. Esto sucedió, según Warren (1977, p. 116), en la década de 1530. Uno de los posibles responsables del traslado pudo ser fray Martín de Jesús, quien estuvo como guardián del convento de Tzintzuntzan de 1526 a 1536 y como custodio entre 1536 y 1539. Un hombre que según Rea (1982) "levantó iglesias, erigió altares y administró los sacramentos, quedando la fe asentada en todo Michoacán y Jalisco por él” (p. 96). También pudo participar fray Ángel de Salcedo, quien fue guardián del mismo convento después de fray Martín, o fray Juan de San Miguel, quien es bien conocido por sus fundaciones, o bien, fray Jerónimo de Alcalá, quien estuvo en Tzintzuntzan en 1533 hasta que fue nombrado guardián del convento de Pátzcuaro, unos años después (Warren, 1977, p. 116).

\section{(ㅇ)(1) $(9$}


Se piensa que la fecha más probable del traslado habría sido de 1534 a 1538, entre la primera y segunda visita de Quiroga a Tzintzuntzan (Beaumont, 1985, t. II, p. 250). La suposición se basa en el testimonio del alguacil de la misma ciudad Suero Asturiano, quien afirmó que desde que el propio obispo había dejado la primitiva iglesia, los franciscanos habían movido dos veces el convento. Según pruebas solicitadas por Quiroga en 1538, la iglesia de los franciscanos que le habían asignado como sede de su obispado estaba en un valle hondo y lleno de barrancas, entre dos cerros y cercado casi todo de una laguna de mala conservación donde reinaba un aire destemplado, malo, enfermo, y donde se bebía de pozos muy malos, turbios, encenagados y contrarios a la salud, por lo que los moradores, tanto naturales como españoles, estaban muy descontentos (Warren, 1977, p. 116).

Aunque los vestigios actuales del camino que llevaba a la capilla de Santa Ana muestran que era empedrado, había quejas por parte de los españoles debido al problema que representaba para ellos el transitar a caballo o en carretas, en un terreno tan accidentado. Si el convento se pasó de las laderas del cerro Tariácuri al valle, se pudo resolver el problema de la circulación, pero no los otros inconvenientes que mencionaban los testigos de Quiroga, aunque estos debieron ser exagerados, considerando que el obispo tenía la intención de desacreditar la ciudad para poder hacer el traslado de la capital a Pátzcuaro.

De cualquier manera, en el valle había posibilidades de trazar el pueblo de acuerdo con los nuevos ideales del urbanismo europeo, es decir, una traza ortogonal partiendo del convento y templo franciscano, dejando las primeras manzanas y los lotes de mayores dimensiones para los principales del pueblo y para los centros administrativos y sociales. Sin embargo, como se aprecia en los vestigios de la traza actual, la traza ortogonal se sobrepuso a la de los caminos de traza orgánica o irregular de la ciudad prehispánica.

El traslado de la capilla, como ya se dijo, pudo haberse realizado entre 1534, cuando se reconoció a Tzintzuntzan como ciudad de Michoacán, o en 1536, año en que quedó como cabecera de la custodia franciscana de San Pedro y San Pablo y como silla del obispado de Michoacán. Se sabe por un testimonio de 1538 que para ese año los frailes tenían poco de haberse mudado (Warren, 1977, p. 440), es decir, se había trasladado de la ladera del cerro Yahuarato hacia la zona baja de Tzintzuntzan. Es probable que también se

\section{()(1) $(3$}


mudara a esta zona de la ciudad parte de la población que habitaba en las laderas de los cerros Tariácuri y Yahuarato.

Cuando Quiroga hizo la toma de posesión de su obispado, como se dijo, descreditó por completo a Tzintzuntzan por su calidad de agua, "destemplamiento de aires", topografía, entre otros inconvenientes, asegurando que la catedral estaba por mudarse a Pátzcuaro donde no se había hecho una fundación, por lo que propuso, no sólo trasladar la iglesia al barrio de Pátzcuaro, sino congregar en este a todos los naturales que vivían desparramados y separados de los españoles, sin hablar específicamente a qué barrios se refería. De Pátzcuaro dice que este lugar es el idóneo:

Por no haber hasta ahora en la dicha ciudad fundada iglesia ni fundación ni población que de provecho sea, sino todo de prestado y de paja, que está y se contiene el dicho sitio en que protestado tiene lo de mudar y trasladar, según que esta dicho, dentro del sitio y término de la dicha ciudad de Mechuacán, y es una parte y barrio de ella que los naturales llaman Pasquaro [...] Y está señalado y tomado sitio para edificar la iglesia catedral so la invocación de S. Salvador para que allí se junten los naturales de todos los barrios y familias y subjetos de ella en orden política, y por otra parte hacia el levante el barrio de los españoles [...] para que se pueda administrar y administre bien como debe a los vecinos de ella la doctrina cristiana y santos sacramentos estando juntos y congregados en buena policía los naturales, que de otra manera no se les pueden cómodamente administrar por su derramamiento e indisposición de vivienda (Arzobispado, 1986, pp. 255-256).

No se sabe con certeza si en realidad hubo un reacomodo de población en el valle antes de 1538, lo que sí se conoce es que para entonces existía un asentamiento humano en la parte baja de la ciudad y un segundo en el barrio de Santa Ana, sobre la ladera del cerro Tariácuri. Al respecto, Diego Calero dijo ser vecino del barrio de abajo; otros, como Suero Asturiano y Pedro Moreno, afirmaron que no se atrevían a subir la cuesta para ir a misa y que preferían ir a la iglesia de San Francisco por ser más llano el camino (Warren, 1977, pp. 443, 445-446).

Tal como lo ilustró Beaumont y de acuerdo con las ordenanzas, la morfología del pueblo hacia el norte de los cerros antes referidos es efectivamente ortogonal, con vías rectas y amplias que van de norte a sur $y$ de oriente

\section{()(1) $\$$}


a poniente. Parece lógico que se hayan trazado las calles y repartido los solares poco después del traslado del convento y templo de Santa Ana al valle, pues esa era la forma común de proceder, como se ha dicho en el ejemplo de la fundación de Acámbaro. Pero al parecer este reacomodo sólo fue parcial pues seguía existiendo al menos un barrio en la parte alta y no se sabe que los sujetos que se ubicaban de una a cuatro leguas de distancia de la cabecera hayan sido congregados (véase mapa 1 ).

\section{LOS BARRIOS DE TZINTZUNTZAN A FINALES DEL SIGLO XVI}

En dos documentos - uno del 14 de febrero de 1595 y otro del 22 de febrero del mismo año-, se puede leer que Tzintzuntzan estaba conformada por los barrios de Santa Ana, San Bartolomé, La Trinidad, San Pablo, San Juan y La Magdalena, por lo que tenían derecho de rotarse los cargos políticos de la ciudad. ${ }^{2}$ Esto nos lleva a pensar que los dos grandes barrios, de abajo y de arriba, se subdividieron y adoptaron nombres de cristianos o que eran barrios que fueron congregados en la cabecera después de 1538 y antes de 1595.

Según la tradición local, en la época colonial existían nueve barrios o más en la cabecera de Tzintzuntzan, que contaban con su propia capilla y sus respectivas imágenes que habían llevado consigo cuando fueron congregados y eran sacadas únicamente para las procesiones de Semana Santa por el atrio y por las principales calles de la ciudad. Se trataba de los barrios de Santa Ana, La Magdalena, San Mateo, San Pedro, San Juan, Santo Santiago, San Pablo, San Bartolomé, San Miguel y La Santísima Trinidad. Dice Alberto Rendón (1980, pp. 225-227) que a varios de estos se les había dado un nombre cristiano. El barrio de Inixurin, en las laderas del cerro Tariácuri se convirtió en Santa Ana; el de Yahuaro se convirtió en San Bartolo o Bartolo-

${ }^{2}$ Mandamiento para que se haga elección de gobernador, regidores, mayordomos y otros oficiales. 14 de febrero de 1595. Instituciones coloniales. Real Audiencia. Indios (058). Contenedor 04, vol. 6, exp. 956, fs. 259v.-260r. Archivo General de la Nación (AGN), México. Todavía en documentos del siglo XVIII y principios del XIX, se mencionan constantemente los barrios de San Pablo, San Bartholomé y La Magdalena. Parece ser que eran los únicos que quedaban. Libro $1^{\circ}$ a $7^{\circ}$ de informaciones matrimoniales. 1709-1816. Archivo Parroquial de Tzintzuntzan (APT), Michoacán, México. Libro $1^{\circ}$ de entierros. 1781-1815. APT, Michoacán, México.

\section{()(1) $\$$}




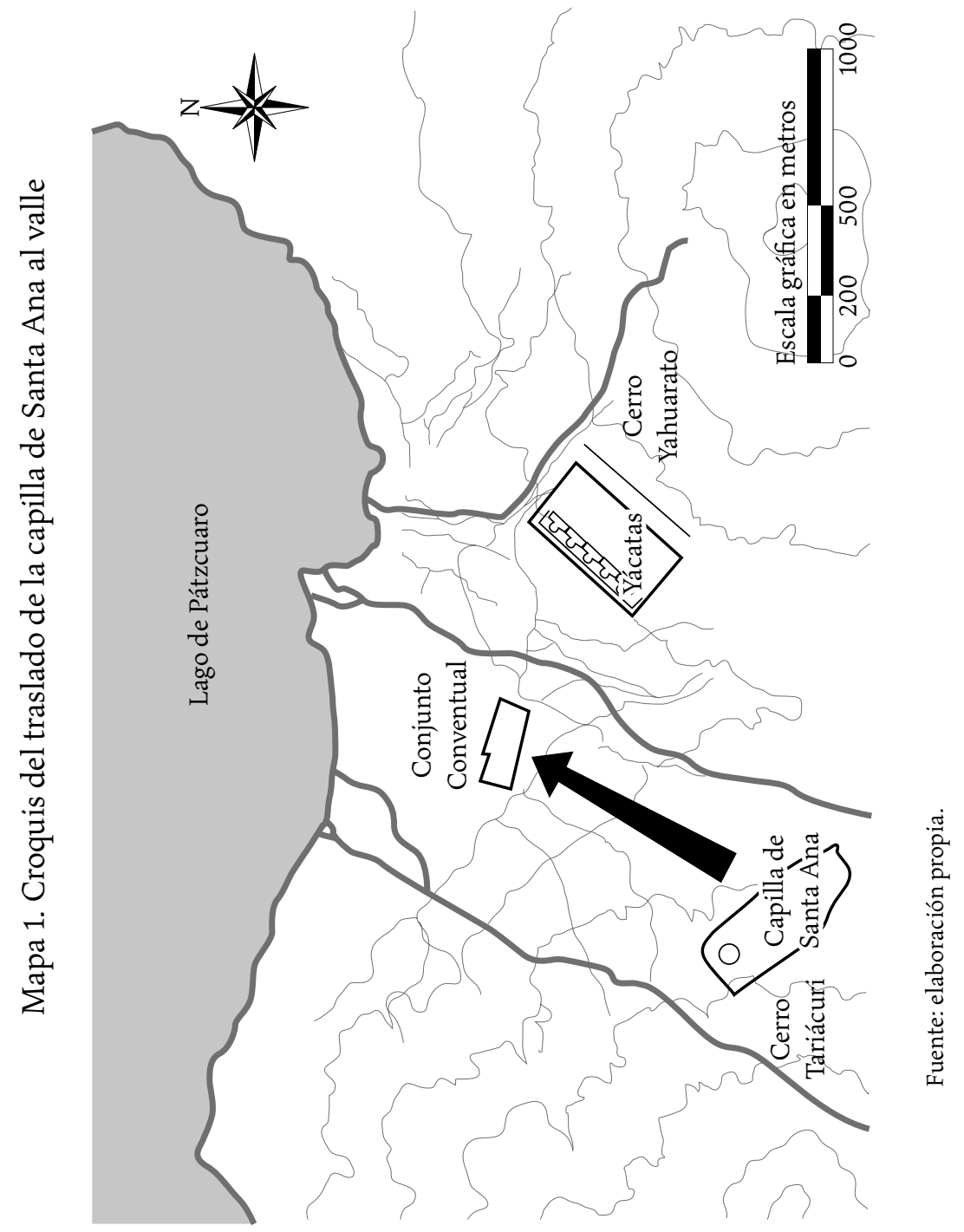

\section{(c) $\$$}


mé; la zona donde se ubicaban Xorio y Mayápeto se conoció como San Pablo; lo que fue Maritaro se convirtió en Santo Santiago, y el de Urápiti-huato se conoció como San Lorenzo.

Los nombres de algunos de ellos corresponden con los que estaban sujetos a Tzintzuntzan a mediados del siglo XVI, a saber: Santa Ana, Santa María Magdalena, San Mateo, San Pedro Tito, San Pedro Uchuchari, San Juan Evangelista, San Juan Vomecuaro o Umecuaro, San Juan Ucao (Ucas o Uca), Santiago Sanambo (Sananbo o Sacamvo), Santiago Arameo, San Pablo, San Bartolomé Atzimbo, San Miguel Cutzaro (Cuicaro), La Trinidad, Pacandan, San Pedro Yacureo, San Sebastián, San Andrés Tziróndaro (Cirangan, Zangan o ¿Tzintzangan?), Santa María Asunción de Cocupao, San Broyavaru, San Cosme, San Francisco Sirandagacho, Genscuaro o Quengenscuaro, Santa María Asunción Tzipisxu, Quanemao o Quenemao o Quenemaquen, Sangatacu (Tzingatacu o Vangatacuo), Santo Tomás Tacupan o Santa María Natividad Tacupen, Santo Tomás Sinchutacu, Ysiparamucu de los Reyes, Los Tres Reyes, Cucuchucho (Cucuchao), San Francisco Higuatzio (Yuatsio, Huguaseo, Ivaseo o Iraceo (Paredes et al., 1994, pp. 75-76). Este último habitado por familias de origen mexica. Muchos de ellos no vuelven a mencionarse en documentos posteriores o se afirma que fueron congregados, como se verá más adelante.

El 17 de enero de 1595 el gobernador de Tzintzuntzan y el guardián de dicha ciudad enviaron una petición al virrey don Luis de Velasco en la que le planteaban la conveniencia de que los barrios sujetos a la recién confirmada ciudad fueran congregados -o reducidos- en la cabecera para que los naturales pudieran vivir en policía y ser doctrinados con más facilidad y utilidad para ellos. En respuesta, el virrey mandó al gobernador y al guardián que congregaran a la brevedad a los naturales de los pueblos sujetos y visitas en las partes que les pareciera más conveniente, sin vejarlos (Paredes et al., 1994, pp. 429-430). Es de llamar la atención que el gobernador y el guardián del convento de Tzintzuntzan hayan solicitado la congregación y que el virrey les haya confiado ejecutarla a ellos y no a un juez congregador como se hacía regularmente. Al parecer el guardián de Tzintzuntzan para entonces era fray Francisco de Aboitiz. Se sabe de él que un año antes había sido guardián del convento de San Juan Peribán, en donde había tenido la experiencia de participar en la congregación de sus pueblos sujetos. Probablemente esa experiencia fue determinante para que el virrey tuviera la confianza de hacerlo

\section{()(1) $(2$}


partícipe de la congregación de los pueblos sujetos a Tzintzuntzan (Paredes, Cárdenas, Piñón y Pulido, 1994, p. 419).

Sin embargo, en diciembre de 1598 el virrey Gaspar de Zúñiga y Acevedo ordenó que se congregaran algunos pueblos de Michoacán, y otra vez se incluye la ciudad de Tzintzuntzan. Si la reducción de 1595 no tuvo efecto o estaba incompleta, probablemente las acciones emprendidas entre 1598 y 1604 fueron más eficientes, pues muchas de las tierras dejadas fueron adquiridas por empresarios españoles, para levantar haciendas y ranchos que seguían perteneciendo a la jurisdicción política y religiosa de Tzintzuntzan, como sucedió en Santiago Atzimbo, Cuenembo, Tziparamuco, Sirandangacho, Tziranga, San Lorenzo, La Trinidad y San Antonio Tacupan - que eventualmente había tenido la advocación de Santo Tomás y Santa María Natividad-. ${ }^{3}$ Esta última, que se encontraba entre los límites de Tzintzuntzan y Pátzcuaro, en el valle de Chapultepec, fue comprada por Juan Díaz Barriga a un habitante de Tzintzuntzan de nombre Bartolomé Méndez Pacheco en 1694, "donde había estado un pueblo congregado a Tzintzuntzan" (Castro, 2004, p. 164).

Mediante un documento expedido por el virrey y dirigido al alcalde mayor de la provincia de Michoacán, Fernando de Villegas, en 1601 y al juez congregador don Luis de Contreras, en 1603, se les instruía para que en presencia de los ministros de justicia y doctrina se siguiera el procedimiento expreso sin pretender algún cambio que no fuera consultado primero con el virrey. Que se pidiera siempre la opinión del ministro de doctrina. Que se reuniera a los indios de la cabecera y los pueblos sujetos para ponerlos al tanto de la congregación, explicarles las razones y procedimiento a seguir. Para ello tenían que valerse del ministro de doctrina quien los persuadiría, a través de pláticas y sermones, de la justicia y utilidad de ser congregados, así como para animarlos a trabajar en la fabricación de sus nuevas casas, templo, casa de cabildo, cárcel y casa de comunidad. Que cada pueblo fuera acomodado en una calle. Que hubiese una plaza junto a la iglesia y que se tuviera agua para ser conducida a las fuentes públicas y casas. Que se trazaran los solares de 25 varas cuadradas, dando un tercio más a los principales; todos dejando

3 Bartolomé Pacheco vende a Juan Díaz Barriga la hacienda de San Andrés Tacupan. 1694. Protocolos. Caja 17, carpeta 3, fs. 52-54. Archivo Histórico de la Ciudad de Pátzcuaro (АнСР), Michoacán, México.

\section{()(1) $(9$}


espacio para árboles y siembra de maíz, chile y legumbres. Que se construyeran las casas en cuadrillas, si era posible con ayuda de pueblos cercanos que no tuvieran obra. Que en el repartimiento se dejara a los indios principales las tierras más cercanas al pueblo y un tercio más grandes que las del resto. Si hubiere tierras de españoles se les quitara y a estos se les mandara con el virrey para recompensarlos. Que se informara sobre españoles y mestizos para valorar si eran perjudiciales o no para los indios. Que se nombrara un alguacil por cada pueblo congregado, de entre ellos mismos, para encargarse de que los indios acudieran a la doctrina, así como para cobrar el servicio y tributos. Para evitar que los congregados regresaran a sus antiguos pueblos se pedía a los gobernadores y oficiales que pusieran atención y avisaran cualquier anomalía y que se deshicieran las iglesias de los pueblos deshabitados, con consentimiento de los ministros y obispo, haciendo un inventario de imágenes, plata, ornamentos y campanas, aprovechando lo necesario en la nueva iglesia. Que en el sitio donde estuvo el altar mayor de la iglesia se pusiera una cruz alta de palo. ${ }^{4}$

Además, como ya se había hecho, por el virrey Luis de Velasco en 1560, se reconocía que las tierras dejadas por los pueblos congregados les seguían perteneciendo. Aun con esta indicación se les seguían dando mercedes a los españoles. Esto dio pie a que tiempo después algunos pueblos regresaran a sus antiguos asentamientos y que se emprendieran juicios contra los españoles que habían adquirido las tierras.

Distintos documentos del siglo Xvir y posteriores afirman que sí hubo una congregación en Tzintzuntzan. Uno de ellos es un expediente que da fe de un pleito por el puesto y tierras de San Lorenzo entre los agustinos de Pátzcuaro y la república de indios de Tzintzuntzan a principios del siglo xVIII. Los tzintzuntzeños declararon a su favor que los tecos de San Lorenzo habían sido congregados en su ciudad, dejándoles la posesión de sus tierras que habían tenido en tiempos inmemorables, por lo que pedían que en conformidad con las ordenanzas y mandatos expedidos por el virrey conde de

4 A don Luis de Castro juez de congregaciones de la provincia de Mechoacán. Tierras, vol. 71, exp. 2, fs. 164-170v. AGN, México. 
Monterrey y el de Montesclaros, se mandara a los españoles no molestarlos ${ }^{5}$ (véase mapa 2).

Según un censo del siglo XVII, para 1631 la ciudad tenía 300 vecinos, más 100 con sus sujetos, que eran sólo Ihuatzio y Cucuchucho, más 20 haciendas y ocho ranchos (López, 1973). Para 1680 Tzintzuntzan tenía tres barrios grandes adoctrinados, que eran Cocupao, Ihuatzio y Cucuchucho, con 17 capillas (Carrillo, 1992, p. 102). No queda claro en este informe si las capillas se encontraban en los tres barrios sujetos y las haciendas o la mayoría en la cabecera, representando a cada uno de los pueblos o barrios del siglo XVI. ¿Los vestigios de dos capillas coloniales encontradas por Román Piña Chan y Rubén Cabrera entre 1977 y 1978 pueden ser parte de estas 17? (Hernández, 2010).

\section{EL REACOMODO DE LA POBLACIÓN DE FINALES DEL SIGLO XVI}

En 1593, después de décadas de lucha, Tzintzuntzan había dejado de ser sujeto de Pátzcuaro, al obtener el reconocimiento como ciudad con título y escudo de armas, mediante dos cédulas reales, una firmada el 3 de noviembre en San Lorenzo, que declaraba que Tzintzuntzan siempre había sido cabecera de la provincia, sede de los reyes y de la Corte tarasca, por lo que se mandaba ser gobernada "con policía y en forma de república bien ordenada"; la otra, signada el 22 de noviembre de 1593 en el Pardo, que le otorgaba independencia de Pátzcuaro y facultad para contar con gobernador propio (Beaumont, 1985, t. II, p. 250). Esto le permitía tener una jerarquía y privilegios que podía compartir con sus pueblos sujetos y los que fueran congregados. Dos años más tarde estaba en condiciones de elegir sus propios gobernadores, alcaldes, regidores, mayordomos, alguaciles y oficiales de república, así como tener su propia organización para cobrar el tributo real. Estas condiciones parecen haber motivado a organizar no sólo el manejo político administrativo de la ciudad, sino también la de los barrios sujetos, congregándolos en la

5 Problema que tienen los naturales de Tzintzuntzan con el convento de San Agustín de Pátzcuaro por un sitio de tierra llamado San Lorenzo. 1710-1719. Caja 19 B, folder 4, 38 fs. AGN, México.

\section{(ㅇ)(1) $(3$}




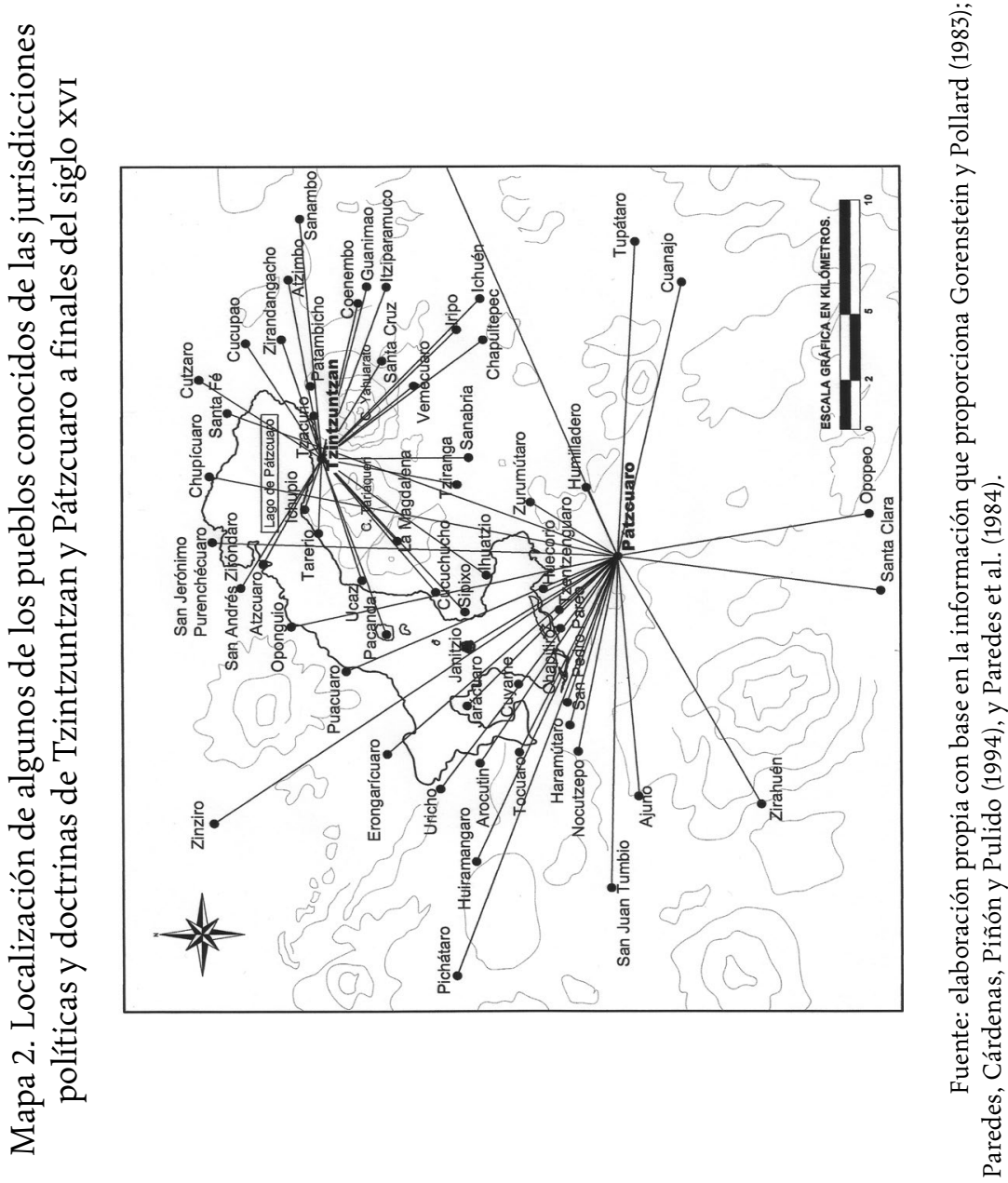

\section{(ㅇ)(1) $\$$}


cabecera. Coincide también con la fecha de terminación del último convento, cuya gestión se le atribuye a uno de sus guardianes: fray Pedro de Pila, que había llegado a convertirse en comisario general de los franciscanos en Nueva España.

En su crónica, Espinosa deja ver que había un interés personal por parte de fray Pedro de Pila para que Tzintzuntzan tuviera un convento y un templo ejemplares, para que recuperara su título de ciudad, arrebatado por Vasco de Quiroga al trasladar la cabecera diocesana y política a Pátzcuaro entre 1538 y 1540 y, al parecer, para que la población fuera reacomodada, cuando dice que el padre Pila "dio leyes al gobierno de la república en lo político y así en las elecciones de justicia, repartimientos de solares, censos, gracias y donaciones, y hasta en cosas domésticas, era oráculo de las decisiones el Santo Pila" (Espinosa, 2003, pp. 291-292). Torquemada también parece referirse a una congregación, al decir que Pila murió en "su provincia de Mechoacán, en el convento de Cinzonza, casa que había hecho, aumentando el pueblo, trayéndole título de ciudad" (Torquemada, 1983).

De acuerdo con las ordenanzas para la reducción o congregación de pueblos a finales del siglo xvi, Tzintzuntzan no se movió de lugar, ya que el hecho de tener el rango de ciudad le prestaba una importancia superior a la del resto de los pueblos de la laguna, a excepción de Pátzcuaro. Además, según las mismas disposiciones, gracias a su número de habitantes y el hecho de tener un convento de frailes con categoría de guardianía -que se había concluido a finales del siglo XVI- lo descartaban de ser trasladado. Por el contrario, los barrios que pertenecían a su doctrina, que contaban con pocos habitantes, tuvieron que integrarse a la cabecera.

Al parecer la congregación de 1598-1603 tuvo efecto esta vez, ya que muchos de sus barrios sujetos a mediados del siglo XVI no se vuelven a mencionar en documentos posteriores. Aunque cabe la posibilidad de que estos sujetos que se hayan desintegrado a causa de las epidemias, como la de 1577, y a migraciones hacia Valladolid, también se sabe que por esta misma razón los barrios que habían quedado con poca población eran congregados a la cabecera.

No se tienen suficientes estudios sobre los perjuicios o beneficios que tuvieron los pueblos congregados en la época colonial, lo que sí se puede ver en varios documentos es que algunos de estos pueblos a partir del siglo XVII fueron protagonistas de continuos y largos procesos en contra de particula-

\section{()(1) $\$$}


res, religiosos agustinos y otros pueblos, para recuperar terrenos que argumentaban haberles pertenecido desde "tiempos inmemorables" o antes de las congragaciones. La legislación reinante en este siglo estaba a favor de que los pueblos conservaran sus tierras. Por desgracia para ellos, los títulos primordiales que los acreditaba como poseedores de determinadas tierras eran imprecisos y más de uno había sido alterado o falsificado (Castro, 2004, pp. 95-98, 208-209).

Al ser congregados, las cabeceras podían exigir a sus sujetos trabajo para obras públicas en las casas reales, iglesias y hospitales, así como servicios personales para la atención de curas párrocos, funcionarios españoles, hospitales y mesones; a cambio podían beneficiarse de los privilegios que gozaba una ciudad. Aun así algunos que se consideraban autosuficientes y con perjuicio al dejar sus tierras, pidieron no ser movidos (Castro, 2004, p. 112). Ihuatzio, por ejemplo, fue uno de los que se resistió a ser trasladado a Tzintzuntzan; en su lugar pedían ser congregados en el barrio de San Bernardino de Pátzcuaro, donde se estaba haciendo otra congregación. ${ }^{6}$ Los indios de este pueblo alegaban que de allí a sus tierras y puesto había muy poca distancia y con facilidad podrían desde San Bernardino gozar y cultivar sus tierras. Aseguraban que los frailes de Tzintzuntzan nunca los habían administrado ni adoctrinado sino los curas de Pátzcuaro. El virrey, a través de su secretario Pedro de Campos, ordenó que fueran congregados en el barrio de San Francisco de Pátzcuaro y se les construyeran sus casas. Más tarde el fallo fue más benévolo y se les permitió congregarse donde ellos quisieran. Parece ser que la indecisión y tolerancia de las autoridades les dio pie para no moverse de su lugar original o regresarse al mismo después de un tiempo, como lo hicieron varios pueblos (véase mapa 3).

Uno de ellos fue San Pedro Cucuchucho, que fue congregado en Tzintzuntzan y después regresó a su lugar original. Sobre este caso encontramos un testimonio de los oficiales de república y mandones del pueblo, quienes en 1634 se quejan ante el alcalde mayor para que los tzintzuntzeños no les pidieran regresar a los indígenas que habían huido a su pueblo de origen por

${ }^{6}$ Este barrio se encontraba entre un cerro, el lago, la hacienda de San Nicolás de los agustinos y Tzurumútaro. Sobre congregación de los indios de Ihuatzio y padrón de ellos. 1602. Serie Michoacán. Rollo 6 (117), f. 10. Biblioteca Nacional de Antropología e Historia (BNAH), México.

\section{()(1) $(3$}




\section{SECUENCIA}

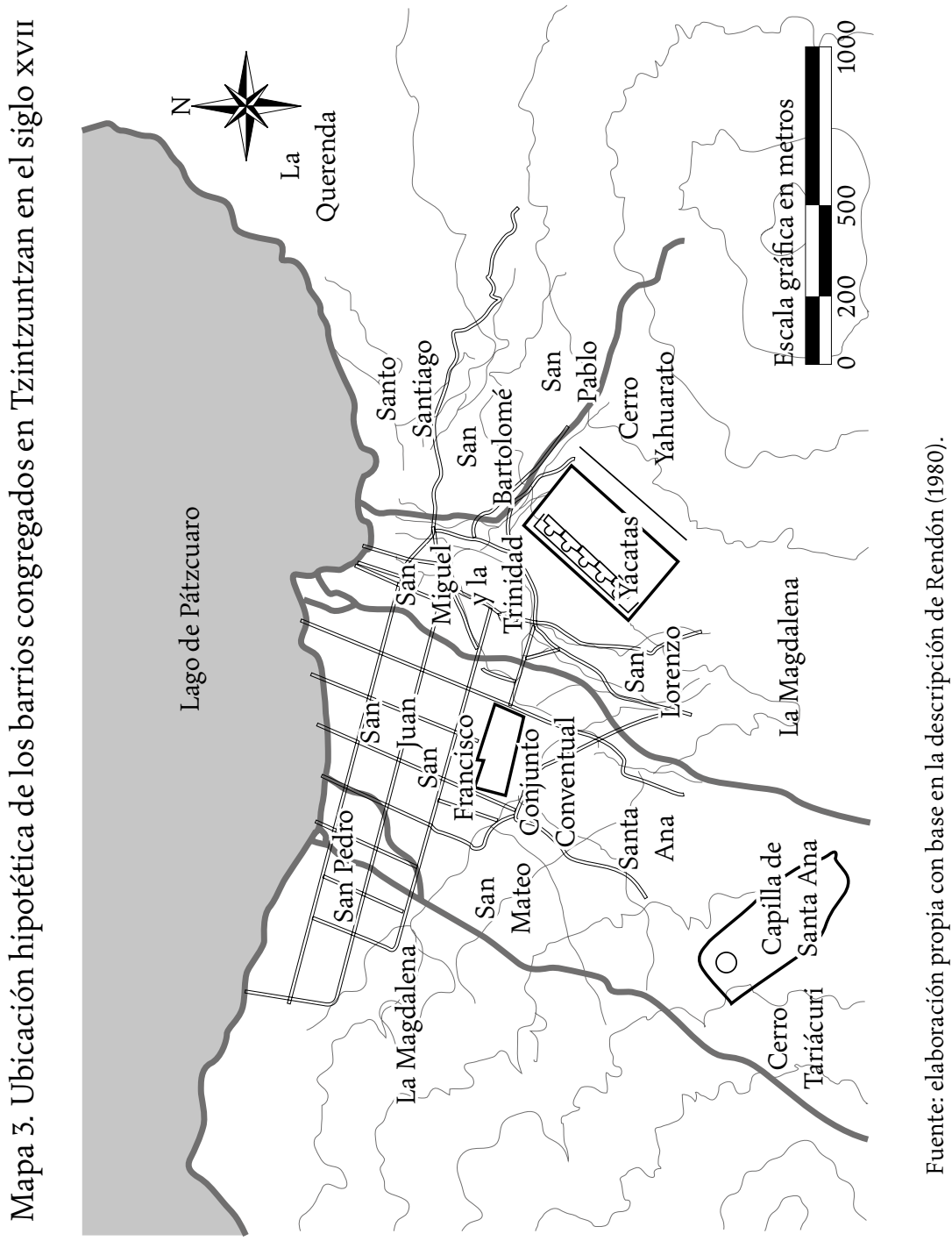

\section{(ㅇ)(1) 8}


"utilidad que se sigue a nuestro común les hemos dado común consentimiento a todos los naturales del dicho pueblo [...] tierras y sitos para que labren casas y siembren sus sementeras".

Otros pueblos fueron movidos a poca distancia de su enclave original, captando población de barrios cercanos de menor jerarquía, como fue el caso de Cocupao, que se congregó el 22 de marzo de 1603, "bajándolo de la loma” y agregándole los pueblos de Sirandangacho y Sanambo, por lo que un tiempo llevó el nombre de Cocupao -Sanambo-Zirandangacho. Los comisionados para esta congregación fueron Baltazar Dorantes de Carranza, el gobernador de Tzintzuntzan Francisco de Pila, Agustín Cuntzi, indio, y Diego Felipe Tzintziqui, prioste del pueblo de Sanambo. ${ }^{8}$ Aunque los habitantes de estos pueblos habían sido movidos reclamaron sus tierras, logrando poco después se les restituyeran legalmente (Brand, 1951, pp. 21-23).

A principios del siglo XVII, Cocupao se organizó en cuatro barrios: San Bartolomé, San Francisco, San Miguel y La Asunción (Díez, 1932, p. 132), quizá correspondiendo con los pueblos congregados de San Bartolomé Atzimbo, San Francisco Sirandangacho (Sirandangachuen), San Miguel Cutzaro, y La Asunción de Cocupao, que habían sido sujetos de Tzintzuntzan tiempo atrás (Paredes et al., 1994, pp. 429-430).

\section{CONCLUSIÓN}

Las congregaciones llevadas a cabo por las autoridades españolas de Nueva España en distintas etapas tuvieron un sustancial impacto en la organización no sólo espacial sino social y económica entre los pueblos de indios. El caso particular de Tzintzuntzan es insólito, ya que el propio gobernador y el guardián del convento franciscano solicitaron al virrey don Luis de Velasco que los barrios sujetos fueran congregados a la cabecera.

${ }^{7}$ Juan Sisique, teniente de gobernador de Cocuchuchao y oficiales de república dicen que de algún tiempo a esta parte se han avecindado en su pueblo algunos naturales de Tzintzuntzan, y el gobernador de esta ciudad los apremia a que se regresen. Piden que no sean molestados ni inquietados, pagando los tributos y servicios personales a Tzintzuntzan. 1634. Caja 9, carpeta 5, f. 1f. AнсP, Michoacán, México.

8 Título de San Diego Cocupao de 1681 y congregación de 1603. Fondo José Corona Núñez. Serie Escritos. Caja 18, exp. 24, fs. 3 y 4. Ahdirh-umsnh, Morelia, Michoacán.

\section{()(1) $\$$}


Aunque a principios del siglo xvis la mayoría de los pueblos de indios habían sido reacomodados, como lo afirmó el virrey al informar que estos estaban congregados "en los dos tercios de la Nueva España y el resto [estaban] reduciéndose" (Pérez, 2009, p. 44), no se conoce hasta ahora el acta de congregación de Tzintzuntzan, por lo que no se tiene certeza de que esta se halla llevado a efecto. Sin embargo, el cruce de información, como lo son diversos testimonios solicitados por don Vasco de Quiroga en 1538, la tradición oral, los hechos históricos plasmados en documentos de archivo y estudios previos, la traza de la ciudad en combinación con los vestigios prehispánicos y la cartografía histórica, nos llevan a pensar que Tzintzuntzan tuvo dos momentos de reacomodo de población. El primero, quizá de manera parcial, habría tenido lugar poco antes de 1538, a raíz de que la obtención del título de ciudad, la sede de la custodia de San Pedro y San Pablo y la cabecera del obispado. El segundo debió ejecutarse entre 1598 y 1603, cuando Tzintzuntzan tenía poco de recibir la confirmación de ser ciudad independiente de Pátzcuaro, coincidiendo con la conclusión de su nuevo convento y templo de calicanto. Estas obras fueron posibles gracias a las gestiones de fray Pedro de Pila, quien se formó en el noviciado de Tzintzuntzan, fue guardián del mismo y, para entonces, ocupaba el puesto más importante entre los franciscanos de Nueva España: el de comisario general (Martínez, 2015).

Las implicaciones al congregar a los pueblos sujetos de Tzintzuntzan en la cabecera pudieron ser similares a las que se tuvieron en otros lugares, como el hecho de que sus tierras desamparadas pasaron a manos de españoles para formar haciendas y ranchos, lo cual más tarde fue motivo de interminables pleitos legales. No obstante, a diferencia con lo que ocurrió con algunos pueblos que eran seriamente afectados al ser movidos a sitios con un clima muy distinto al que estaban acostumbrados, e incluso que fueron congregados con pueblos rivales o de distinta etnia, los pueblos sujetos a Tzintzuntzan habían sido movidos a poca distancia, eran adoctrinados por los mismos religiosos y, a excepción de unos pocos, como San Lorenzo y La Magdalena, la mayoría pertenecía a la misma etnia y habían convivido con los purépechas de Tzintzuntzan por mucho tiempo. Como lo señala la tradición oral, los pueblos congregados en una misma calle o barrio tenían su propia capilla y su propio cristo que sacaban en las procesiones de Semana Santa, pero sobre todo tenían derecho de rotarse los

\section{()(1) $(9$}


cargos políticos de la ciudad, un privilegio del que no gozaban al ser sujetos fuera de la cabecera.

Por desgracia, poco se ha estudiado sobre las congregaciones en la ribera del lago de Pátzcuaro. Las exploraciones arqueológicas, mapeo y levantamientos realizados por Helen Pollard, Román Piña Chan, Eugenia Fernández y Efraín Cárdenas proporcionan información valiosa pero incompleta para entender más sobre las transformaciones urbanas de Tzintzuntzan y su entorno durante el primer siglo después de la llegada de los primeros españoles a la entonces capital tarasca.

\section{LISTA DE REFERENCIAS}

Alcalá, J. (1980). La relación de Michoacán. Morelia: Fimax.

Arvizu, C. (1993). Urbanismo novohispano en el siglo XVI. Querétaro: Fondo Editorial de Querétaro.

Arzobispado de Morelia (1986). Vasco de Quiroga y el obispado de Michoacán, 1536-1986. Morelia: Edición pastoral del 450 aniversario.

Beaumont, P. (1985). Crónica de Michoacán (3 tt.). Morelia: Balsal.

Brand, D. (1951). Quiroga a Mexican municipio. Washington: Smithsonian Institution. Carrillo, A. (1992). Partidos y padrones del obispado de Michoacán 1680-1685. Zamora: El Colegio de Michoacán/Gobierno del Estado de Michoacán.

Castro, F. (2004). Los tarascos y el imperio español, 1600-1740. Morelia: UNAM/UMNSH.

Díez de la Calle, J. (1932). Memoria de noticias sacras y reales del imperio de las Indias Occidentales. Madrid.

Escobar, M. (2008). Americana Thebaida. Morelia: IIH-UmsnH/Morevallado.

Espinosa, I. (2003). Crónica apostólica y seraphica de todos los colegios de propaganda Fide de esta Nueva España. Querétaro: Gobierno del Estado de Querétaro.

Gerhard, P. (1986). Geografía histórica de la Nueva España 1519-1821. México: unAm.

Gorenstein, S. y Pollard, H. (1983). The Tarascan civilization: A late prehispanic cultural system. Nashville: Vanderbilt University (Publications in Anthropology, 28).

Hernández, V. (2010). El reúso colonial de los janamus en Tzintzuntzan, Michoacán. Una exaltación del pasado prehispánico. Anales del Instituto de Investigaciones Estéticas, XXXII(96), 6-35. Recuperado de http://www.analesiie.unam.mx/index.php/ analesiie/article/view/2305/2595

López, R. (1973). El obispado de Michoacán en el siglo XVII. Morelia: Fimax.

\section{()ㅜ(1) $\$$}


Martínez, J. (2015). Fray Pedro de Pila y su obra en Tzintzuntzan. Anuario de Historia de la Iglesia (24), 383-403. Universidad de Navarra. Dor: 10.15581/007.24.383-403

Paredes, C. et al. (1984). Michoacán en el siglo XVI. Morelia: Fimax publicistas (Colección Estudios Michoacanos).

Paredes, C., Cárdenas, V., Piñón, I. y Pulido, T. (1994). Y por mi visto... mandamientos, ordenanzas, licencias y otras disposiciones virreinales sobre Michoacán en el siglo XVI. México: Ciesas/umsnh/Ediciones de la Casa Chata.

Paso y Troncoso, F. del (comp.) (1939-1942). Epistolario de la Nueva España. 1505-1818. Vol. 8. México: Antigua Librería Robredo de José Porrúa e Hijos.

Pérez Zevallos, J. M. (2009). Las reubicaciones tempranas en México. La reubicación de la población indígena en la Nueva España (siglos XVI-XVII) (pp. 19-48). En J. M. Macías M. (coord.), Investigación evaluativa de reubicaciones humanas por desastres en México. México: ciesas/Sedesol/Conacyt.

Pollard, H. (1977). An analysis of urban zoning and planning at prehispanic Tzintzuntzan. American Philosophical Society, cxxI(1). Recuperado de http://www.jstor. org/stable/986566

Rea, A. de la (1982). Crónica de la orden de Nuestro Seráfico Padre San Francisco Provincia de San Pedro y San Pablo de Michoacán en la Nueva España. México: La Voz de México.

Rendón, A. (1980). Tzintzuntzan, breve reseña histórica y turística. México: Fonapas.

Rubial, A. (1990). La vida religiosa en el México colonial. Un acercamiento bibliográfico. México: Universidad Iberoamericana.

Salazar, G. (2008). Ordenamiento espacial del territorio en el antiguo obispado de Michoacán. En E. M. Azevedo Salomao y C. S. Paredes Martínez (dir.), Del territorio a la arquitectura en el obispado de Michoacán. Morelia: UMSNH/CONACYT.

Torre, E. de la (1995). Las congregaciones de los pueblos de indios. México: unAM.

Torquemada, J. de (1983). Monarquía indiana (7 vols.). Miguel León Portilla (ed.). MéXiCo: IIH-UNAM.

Warren, B. (1977). La conquista de Michoacán 1521-1530. Morelia: Fimax.

Warren, B. (1997). Vasco de Quiroga y sus pueblos hospitales de Santa Fe. México: Ediciones Hidalgo/umsNH. 


\section{OTRAS FUENTES}

AGN

AHDIIH-UMSNH

AHCP

APT

BNAH
Archivo General de la Nación, México.

Archivo Histórico Documental del Instituto de Investigaciones Históricas-Universidad Michoacana de San Nicolás de Hidalgo. Morelia, México.

Archivo Histórico de la Ciudad de Pátzcuaro, Michoacán, México. Archivo Parroquial de Tzintzuntzan, Michoacán, México. Biblioteca Nacional de Antropología e Historia, México.

\section{Bibliografía}

Aguayo, R. (ed.) (1940). Don Vasco de Quiroga. Documentos. México: Polis.

Becerril, R. y Cerda, I. (2005). Catálogo de documentos históricos coloniales de Michoacán. Expedientes microfilmados y reproducidos. México: UMSNH/Secretaría de Difusión Cultural y Extensión Universitaria.

Ciudad Real, A. de (1976). Tratado curioso y docto de las grandezas de la Nueva España. Relación breve y verdadera de algunas cosas de las muchas que sucedieron al padre fray Alonso Ponce [...]. J. García Quintana y V. M. Castillo Farreras (eds.) (2 vols.). México: UNAM.

Dorantes, B. (1902). Sumada relación de las cosas de la Nueva España, con noticia individual de los descendientes legítimos de los conquistadores y primeros pobladores españoles mexicanos. México: Imprenta del Museo Nacional.

Fernández-Villanueva, E. (1997). El desarrollo urbano de Tzintzuntzan, época prehispánica y periodo colonial temprano. En C. Paredes Martínez (dir.), Arquitectura y espacio social en poblaciones purépechas de la época colonial (pp. 147-162). Morelia: IIH-UMSNH/Universidad Keio/CIESAs.

Gerhard, P. (1977). Congregaciones de indios en la Nueva España antes de 1570. Historia Mexicana, XXVI(103). Recuperado de http://www.jstor.org/stable/25135561

Muñoz, D. (2000) Descripción de la provincia de los apóstoles San Pedro y San Pablo en las Indias de la Nueva España. En J. Benedict Warren (estudio introductorio y edición). Michoacán en la década de 1580. México: IIH-UMSNH.

\section{()(1) $\$$}

